\title{
Relationship between human papillomavirus status and cervical cytological abnormalities in a low risk turkish population
}

\begin{abstract}
Objectives: To investigate the relationship between human papillomavirus (HPV) genotypes and abnormal cytology results in a local Turkish hospital and to review the recent Turkish literature.

Methods: In this cross-sectional study, pap smear and of 7985 patients between October 2012 and September 2014 were reviewed. Patients with abnormal cytology were included in the study. The relationship between HPV status and cervical cytology results were investigated.

Results: One hundred and twelve patients (1.4\%) had abnormal cervical cytology results. Ninety five patients with abnormal cytological results were finally analyzed. Thirty one $(32.6 \%)$ patients were positive for HPV. The mean ages of HPV (+) and HPV (-) patients were comparable ( $42.5 \pm 10.1$ years vs. $44.6 \pm 10.7$ years, respectively; $P=.382)$. Two patients had multiple HPV infections. The most common HPV types were HPV 16 (38.2\%), HPV $6(23.5 \%)$, HPV $18(14.7 \%)$ and HPV $33(9.1 \%)$. The ratio of diagnostic upgrade after histopathologic examination was significantly higher in HPV (+) ASC-US patients than HPV (-) ASC-US patients ( $50 \%$ vs. $5.8 \%$, respectively; $P=.002)$. The ratio of diagnostic upgrade after histopathologic examination was significantly higher in HPV $(+)$ LSIL patients than HPV (-) LSIL patients ( $45.5 \%$ vs. $0 \%$, respectively; $P=.030$ ).
\end{abstract}

Conclusion: While developing national and regional screening and vaccination strategies for cervical cancer it's important to define HPV genotype distribution and its relationship with screening results in different local regions of the country.

Keywords: Cervical cancer, Human papillomavirus, Prevalence, Screening, Smear, Turkey
Volume 8 Issue 3 - 2017

\author{
Yuksel Kurban,' Ibrahim Uyar, ${ }^{2}$ Emre \\ Gnakan,' Mustafa Albayrak,' Nurcihan \\ Karakurt Hascelik' \\ 'Kecioren Research and Training Hospital,Turkey \\ ${ }^{2}$ Tepecik Training and Research Hospital, Turkey
}

\begin{abstract}
Correspondence: Ibrahim Uyar, Department of Obstetrics and Gynecology, Tepecik Training and Research Hospital, Gaziler Street No. 468, 35500 Yenisehir, Izmir, Turkey, Tel 9002324494949,Email iuyar@yahoo.com
\end{abstract}

Received: June 06, 2017 | Published: December 18, 2017
Abbreviations: CC, Cervical Cancer; Pap, Papanicolau; HPV, Human Papilloma Virus; CIN, Cervical Intraepithelial Neoplasia; HSIL, High-Grade Squamous Intraepithelial Lesions; PCR, Polymerase Chain Reaction; ASC-US, Atypical Squamous Cells of Undetermined Significance; LSIL, Low-Grade Squamous Intraepithelial Lesions; HC, Hybrid Capture

\section{Introduction}

Cervical cancer (CC) is the fourth most common cancer among women worldwide and deaths from CC accounts for $7.5 \%$ of all female cancer deaths. ${ }^{1}$ Population based screening by Papanicolau (Pap) smear test significantly reduces the incidence of CC and associated mortality in high income countries. However, approximately $75-80 \%$ of CC cases are seen in developing countries where efficient screening is insufficient. ${ }^{2}$ Human papilloma virus (HPV) testing is less specific and more sensitive than traditional Pap smear test and suggested for initial screening in addition to Pap smear in order to decrease false negativity. HPV infection is the most common sexually transmitted disease and leading pathogenic factor for cervical intraepithelial neoplasia (CIN) and $\mathrm{CC}^{3}$ Around $10 \%$ of women worldwide are estimated to be positive for HPV DNA in the cervix and the prevalence increases in less developed regions. ${ }^{4}$ HPV 16 is the most common type irrespective of the diagnosis with an estimated point prevalence of $2.6 \%$ among women with normal cytology. ${ }^{4}$ Infection with HPV increases the risk of abnormal cytological results and the contribution of HPV DNA in high-grade squamous intraepithelial lesions (HSIL) is estimated to be over $85 \% .^{5}$
According to the GLOBOCAN database $\mathrm{CC}$ is the $12^{\text {th }}$ most common cancer among women in Turkey and ranks $15^{\text {th }}$ among cancer related deaths. ${ }^{1}$ While HPV prevalence differs due to the geographical location, public structure or type of diagnostic methods, it's not truly defined among Turkish women. HPV genotype distribution among cytological abnormalities in Turkish women is another less known issue. Previously, relationship between HPV genotype and abnormal cytological results were reported from different regions of Turkey in small cohorts.

The aim of the present study was to investigate the relationship between HPV genotypes and abnormal cytology results in a local Turkish hospital and to review the recent Turkish literature.

\section{Materials and methods}

A cross-sectional study was conducted among patients who had screened by Pap smear for cervical pathologies in the out-patients clinic of the Department of Obstetrics and Gynecology at Kecioren Training and Research Hospital, Ankara, Turkey, between October 1, 2012, and September 30, 2014. The study was approved by the institutional ethics committee. The inclusion criteria were age between 21 and 70 years, being non-pregnant, and having an intact uterus. The exclusion criteria were current or previous diagnosis of any cervical squamous intraepithelial lesion, and immune suppression. Samples of exfoliated cervical cells were obtained using a cytobrush and evaluated by cytopathology unit of pathology department according to the 2001 Bethesda system criteria. ${ }^{6}$ Patients who had abnormal 
cervical cytology result were further evaluated by colposcopy and HPV DNA testing. All lesions during the colposcopic evaluations were biopsied, and in case of no lesion random punch biopsies from four quadrants of the cervix were performed. Samples for HPV DNA were taken with a cervical cytobrush prior to colposcopy. HPV DNA genotyping was performed using a multiplex polymerase chain reaction (PCR) system. Eighteen types of high-risk HPV (HPV 16, $18,26,31,33,35,39,45,51,52,53,56,58,59,66,68,73,82)$ and low-risk HPV were investigated.

Patients' demographic characteristics, cervical cytology and colposcopy guided pathology results, HPV status and types were recorded from the charts of patients with abnormal cervical cytology. The distribution of HPV types and histopathologic diagnoses among patients with abnormal cervical cytology were investigated. HPV DNA positive cases and HPV DNA negative controls were compared to examine the association between HPV infection and histopathologic diagnosis in patients with abnormal cervical cytology results.

\section{Statistical analyses}

The data were analyzed using SPSS for Windows, version 15.0 (SPSS Inc, Chicago, IL, USA). Descriptive statistics are presented as percentages or mean \pm standard deviation. Between-group differences were analyzed using $\chi^{2}$ or Fisher exact tests for categorical variables. Continuous variables were evaluated using the Student's $t$ test. $P<.05$ was considered statistically significant.

\section{Results}

During the two year period, overall 7985 cervical cytology reports were evaluated from the patient charts. One hundred and twelve patients $(1.4 \%)$ had abnormal cervical cytology results. The rates of atypical squamous cells of undetermined significance (ASC-US), low-grade squamous intraepithelial lesions (LSIL) and HSIL were $0.90 \%, 0.30 \%$, and $0.13 \%$, respectively. Seventeen patients were not included in the present study. Of those 10 patients with ASC-US were subjected to follow up by the primary physician, and seven patients with LSIL ( $n=4)$ and HSIL ( $n=3$ ) were referred to another hospital by patient desire. Consequently, 95 patients were included in the study. Among those, 62 had ASC-US, three had atypical squamous cellscannot exclude HSIL (ASC-H), 20 had LSIL, eight had HSIL, one had atypical glandular cells (AGC), and one had CC. The mean age of the study population was $43.9 \pm 10.5$ years.

The mean ages of HPV (+) and HPV (-) patients were comparable (42.5 \pm 10.1 years vs. $44.6 \pm 10.7$ years, respectively; $P=.382)$. Also, the rate of HPV positivity was similar between patients $\leq 35$ years and $>35$ years $(31.8 \%$ [7/22] vs. $32.9 \%$ [24/73], respectively; $P=.57)$. Table 1 demonstrates the distribution of HPV genotyping and cervical cytological abnormalities. Overall, $31(32.6 \%)$ patients were positive for HPV. Two patients had multiple infections with HPV 16, 18 and HPV 16, 33, 45. The most common HPV types in our study population were HPV 16 (38.2\%), HPV 6 (23.5\%), HPV 18 (14.7\%) and HPV 33 (9.1\%). Although, the most common HPV type among patients with ASC-US was HPV 6, the most common HPV type in patients with either LSIL or HSIL was HPV 16 (Table 1).

Table 2 illustrates the distribution of cervical cytological abnormalities with regard to histopathologic diagnoses. Among patients with ASC-US, 8 (12.9\%) were upgraded to CIN I or CIN II-III after histopathologic examination. Among patients with LSIL, 5 $(25 \%)$ were upgraded to CIN II-III after histopathologic examination. Also, among patients with HSIL, 5 (62.5\%) were upgraded to cervical cancer after histopathologic examination.

Table I Distribution of HPV genotypes with regard to abnormal cervical cytology

\begin{tabular}{|c|c|c|c|c|c|c|c|}
\hline HPV Genotype & ASC-US n (\%) & ASC-H n (\%) & LSIL n (\%) & HSIL n (\%) & AGC n (\%) & CC n (\%) & Overall n (\%) \\
\hline HPV 16 & $3(4.8)$ & I (33.3) & $3(15)$ & $3(37.5)$ & 0 & $I(100)$ & II (II.6) \\
\hline HPV 6 & $6(9.7)$ & I (33.3) & I (5) & 0 & 0 & 0 & $8(8.4)$ \\
\hline HPV 18 & 0 & I (33.3) & $2(10)$ & I (I2.5) & 0 & 0 & $4(4.2)$ \\
\hline HPV 33 & 0 & 0 & $2(10)$ & 0 & 0 & 0 & $2(2.1)$ \\
\hline HPV II & I (I.6) & 0 & 0 & 0 & 0 & 0 & $I(I)$ \\
\hline HPV 3I & 0 & 0 & 0 & I (I2.5) & 0 & 0 & $I(I)$ \\
\hline HPV 35 & 0 & 0 & I (5) & 0 & 0 & 0 & I (I) \\
\hline HPV 66 & 0 & 0 & I (5) & 0 & 0 & 0 & I (I) \\
\hline HPV I6, I8 & 0 & 0 & 0 & I (I2.5) & 0 & 0 & I (I) \\
\hline HPV $16,33,45$ & 0 & 0 & I (5) & 0 & 0 & 0 & I (I) \\
\hline Negative & $52(83.9)$ & 0 & $9(45)$ & $2(25)$ & I $(100)$ & 0 & $64(67.4)$ \\
\hline
\end{tabular}

HPV: Human Papilloma Virus;ASC-US:Atypical Squamous Cells of Undetermined Significance;ASC-H:Atypical Squamous Cells-Cannot Exclude HSIL; LSIL: Low Grade Squamous Intraepithelial Lesion; HSIL: High Grade Squamous Intraepithelial Lesion;AGC:Atypical Glandular Cells; CC: Cervical Cancer.

Table 2 Distribution of cervical cytological abnormalities with regard to histopathologic diagnoses

\begin{tabular}{lllll}
\hline & Negative & CIN I & CIN II-III & CC \\
\hline ASC-US, n (\%) & $54(87 . I)$ & $6(9.7)$ & $2(3.2)$ & 0 \\
ASC-H, n (\%) & 0 & 0 & $3(100)$ & 0 \\
LSIL, n (\%) & II (55) & $4(20)$ & $5(25)$ & 0 \\
HSIL, n (\%) & $2(25)$ & 0 & $1(12.5)$ & $5(62.5)$ \\
AGC, $n$ (\%) & I (I00) & 0 & 0 & 0 \\
CC, $n$ (\%) & 0 & 0 & 0 & $I(100)$ \\
\hline
\end{tabular}

ASC-US:Atypical Squamous Cells of Undetermined Significance;ASC-H:Atypical Squamous Cells-Cannot Exclude HSIL; LSIL: Low Grade Squamous Intraepithelial Lesion; HSIL: High Grade Squamous Intraepithelial Lesion;AGC: Atypical Glandular Cells; CC: Cervical Cancer; CIN: Cervical Intraepithelial Lesion.

Table 3 summarizes the relationship between HPV status and diagnostic accuracy of cervical cytology. The ratio of diagnostic upgrade after histopathologic examination was significantly higher in HPV (+) ASC-US patients than HPV (-) ASC-US patients $(50 \%$ vs. $5.8 \%$, respectively; $P=.002)$. The ratio of diagnostic upgrade after histopathologic examination was significantly higher in HPV (+) LSIL patients than HPV (-) LSIL patients (45.5\% vs. $0 \%$, respectively; $P=.030)$. Howe.ver, the ratio of diagnostic upgrade after histopathologic examination was similar in HPV (+) and HPV (-) HSIL patients (Table 3). 
Table 3 Effect of HPV status on diagnostic upgrade after histopathologic examination

\begin{tabular}{llll}
\hline Diagnostic Upgrade in & HPV (+) & HPV (-) & P \\
\hline ASC-US, $n(\%)$ & $5 / 10(50)$ & $3 / 52(5.8)$ & 0.002 \\
LSIL, $n(\%)$ & $5 / 11(45.5)$ & $0 / 9(0)$ & 0.03 \\
HSIL, $n(\%)$ & $4 / 6(66.7)$ & $1 / 2(50)$ & 0.643 \\
\hline
\end{tabular}

HPV: Human Papilloma Virus; ASC-US: Atypical Squamous Cells of Undetermined Significance; LSIL: Low Grade Squamous Intraepithelial Lesion; HSIL: High Grade Squamous Intraepithelial Lesion.

\section{Discussion}

The present study aimed to define relationship between abnormal cytological results and HPV genotypes in a local hospital from Turkey. The prevalence of abnormal cytology in the study population was $1.4 \%$ and of these $32.6 \%$ were HPV positive. The most common HPV type was HPV 16. The most common HPV type among patients with ASC-US was HPV 6. The diagnostic upgrade after colposcopic biopsy was significantly higher in HPV (+) ASC-US and LSIL patients than HPV (-) ones.

The prevalence of abnormal cytological results varies according to population characteristics, diagnostic criteria used, and the experience of cytologist. The prevalence of cervical cytological abnormalities varies between $1.5 \%$ and $6 \%$ in high income countries. ${ }^{7}$ Similarly, it's been reported between $0.5 \%$ and $6.3 \%$ in Turkey. ${ }^{8-10}$ The prevalence of abnormal cervical cytology in our study population was also within this range. According to the largest prevalence study from Turkey the rates of ASC-US, LSIL and HSIL were $1.07 \%, 0.30 \%$ and $0.17 \%$, respectively..$^{10}$ In our study these rates were similar with the former report from Turkey except for ASC-US. Although ASC-US is the most common cervical cytological abnormality worldwide, the prevalence of ASC-US in our study $(0.90 \%)$ was a little bit lower than the former Turkish study. ${ }^{7,10}$ This situation might be originating from the differences between the study designs and populations. Although the former study reported records of patients from 33 centers from different regions of Turkey, ours was a single center study from a local hospital. However, the rates of abnormal cytological results were much lower than Western countries, most probably due to the conservative life style of Turkish people because of religious and socio-cultural factors.

The prevalence of HPV infection depends on the population characteristics, geographical region and detection method used. In previous studies from Turkey it's reported similar to Western countries. In a meta-analysis including 576.281 patients from 120 studies HPV prevalence was found $32.1 \%$ worldwide. ${ }^{11}$ In Turkey, the prevalence of HPV was found between 2.1 to $38.9 \%$ in different studies. ${ }^{12-17}$ The HPV infection rate in patients with abnormal cytology is higher. Table 4 summarizes the recent studies with available full-text from Turkey investigating the relationship between HPV status and abnormal cytological results. The previous studies from Turkey reported the rate of HPV infection among patients with abnormal cervical cytology between $12 \%$ and $80 \%{ }^{13-25}$ This wide range probably originated from the detection method used. Earlier studies generally reported results by hybrid capture (HC) II system. Two studies from Ankara using HC II reported that the rate of HPV positivity among patients with abnormal cytology were $12 \%$ and $19 \% .{ }^{14,22}$ However, one study from Izmir, western coast of Turkey, reported HPV in $47 \%$ of patients with abnormal cytology by using HC II system. ${ }^{20}$ This high difference might be a result of regional life-style discrimination. However, the studies using PCR reported higher HPV positive cases among patients with abnormal cytology. ${ }^{13,15-19,21-25}$ We also found HPV in $32.6 \%$ of patients with abnormal cytology and our result was in consistent with the previous literature. Turkey is geographically located between Europe and Asia, but the prevalence and genotypes of HPV are similar to western countries.

Table 4 Recent full-text available Turkish studies investigating the relationship between HPV status and abnormal cytological results

\begin{tabular}{|c|c|c|c|c|c|c|c|c|c|c|}
\hline Study & City \& Year & $\begin{array}{l}\text { Article } \\
\text { Language }\end{array}$ & $\begin{array}{l}\text { Study } \\
\text { Design }\end{array}$ & Method & $\begin{array}{l}\text { Screened } \\
\text { Patients } \\
\text { (n) }\end{array}$ & $\begin{array}{l}\text { RPV } \\
\text { Rate (\%) }\end{array}$ & $\begin{array}{l}\text { No. } \\
\text { Abnormal } \\
\text { Cytology (n) }\end{array}$ & $\begin{array}{l}\text { Age } \\
\text { (Years) }\end{array}$ & $\begin{array}{l}\text { HPV Rate within } \\
\text { Abnormal } \\
\text { Cytology (\%) }\end{array}$ & $\begin{array}{l}\text { Most } \\
\text { Common } \\
\text { HPVType }\end{array}$ \\
\hline Ergünay et al. ${ }^{18}$ & Ankara, 2007 & Turkish & $\mathrm{R}$ & PCR & N/A & N/A & 35 & 43 & 80 & HPV I6 \\
\hline Ergünay et al. ${ }^{19}$ & Ankara, 2008 & Turkish & $\mathrm{R}$ & PCR & N/A & $\mathrm{N} / \mathrm{A}$ & 40 & 44 & 57.5 & HPV 16 \\
\hline Yetimalar et al. ${ }^{20}$ & Izmir, 2009 & Turkish & $\mathrm{R}$ & $\mathrm{HC} ॥$ & $N / A$ & $\mathrm{~N} / \mathrm{A}$ & 85 & $N / A$ & 47 & $N / A$ \\
\hline Dursun et al. ${ }^{21}$ & Ankara, 2009 & English & $\mathrm{R}$ & PCR & 403 & 23 & 93 & 37 & 36 & HPV 16 \\
\hline Eren et al. ${ }^{13}$ & Istanbul, 2010 & English & $P$ & PCR & 492 & 16.5 & 23 & $N / A$ & 73.9 & HPV I6 \\
\hline Özcan et al. ${ }^{14}$ & Ankara, 20II & English & $P$ & $\mathrm{HC} I \mathrm{I}$ & 501 & 4.2 & 21 & 34 & 19 & N/A \\
\hline Kasap et al ${ }^{15}$ & Izmir, 201I & English & $P$ & PCR & 642 & 38.9 & 96 & 36 & 78.1 & $N / A$ \\
\hline Bayramov et al. ${ }^{22}$ & Ankara, 201I & English & $P$ & $\mathrm{HC} \|$ & $N / A$ & $\mathrm{~N} / \mathrm{A}$ & 86 & N/A & 12 & N/A \\
\hline Özalp et al..$^{16}$ & Eskișehir, 201I & English & $P$ & PCR & 615 & 4.2 & 51 & 35 & 13.7 & HPV 16 \\
\hline Eroğlu et al. ${ }^{24}$ & Konya, 20II & Turkish & $\mathrm{R}$ & PCR & $N / A$ & $\mathrm{~N} / \mathrm{A}$ & 91 & 37 & 39.6 & HPV 18 \\
\hline Yüce et al. ${ }^{25}$ & Ankara, 2012 & English & $\mathrm{R}$ & PCR & 890 & 25.7 & 80 & 39 & 48.8 & HPV 16 \\
\hline Çilingir et al. ${ }^{24}$ & Istanbul, 2013 & English & $P$ & PCR & N/A & $\mathrm{N} / \mathrm{A}$ & 76 & 35 & 44.7 & HPV 16 \\
\hline Özdaș et al. ${ }^{22}$ & Ankara, 2013 & Turkish & $P$ & PCR & N/A & $\mathrm{N} / \mathrm{A}$ & 43 & 38 & 30.2 & HPV 16 \\
\hline Avci et al. ${ }^{21}$ & Ankara, 2013 & Turkish & $P$ & PCR & N/A & N/A & 77 & 45 & 61 & HPV 16 \\
\hline Dursun et al. ${ }^{25}$ & $\begin{array}{l}\text { Multicenter, } \\
2013\end{array}$ & English & $\mathrm{R}$ & Both & 6388 & 25 & 1176 & 38 & 53 & HPV 16 \\
\hline Tezcan et al. ${ }^{17}$ & Mersin, 2014 & English & $P$ & PCR & 476 & 22.3 & 96 & 43 & 35.4 & HPV 66 \\
\hline Present study & Ankara, 2015 & English & $\mathrm{R}$ & PCR & 7985 & $N / A$ & 95 & 43 & 32.6 & HPV 16 \\
\hline
\end{tabular}

R: Retrospective; P: Prospective; PCR: Polymerase Chain Reaction; HC II: Hybrid Capture II, HPV: Human Papilloma Virus. 
The most common HPV types are HPV 16 (9.5\%) and HPV 18 $(6.2 \%)$ worldwide ${ }^{11}$ However, in our study population with abnormal cytological results the most common HPV types were HPV 16, HPV 6 and HPV 18. According to the previous reports from Turkey HPV 16 is the most prevalent type among patients with abnormal cytology irrespective of the region (Table 4). Interestingly, in studies from Mersin the most prevalent types were reported as HPV $66{ }^{17}$ Although these studies are from different regions, the reason for inconsistent ratios might also be low number of patients included in those analyses In the present study, we identified that the most common infection in patients with ASC-US was HPV 6. This result clearly demonstrates that HPV 6 is associated with lower grade lesions and HPV 16 and HPV 18 are associated with higher grade lesions. According to the results of the present study presence of HPV infection is significantly associated with diagnostic up-grade after colposcopic biopsy in patients with ASC-US and LSIL. In addition, after histopathological examination of HSIL patient's micro invasive cancer was diagnosed as a high rate of $62.5 \%$. HSIL Patients should be performed with diagnostic procedure for the possibility of underlying micro invasive cancer co-existences.

In our study, out of $31 \mathrm{HPV}(+)$ patients two had multiple HPV infections $(6.4 \%)$. The ratio of multiple HPV infection was lower than the previous reports from Turkey. Yüce et al..$^{23}$ reported multiple HPV infection in $10 \%$ of patients with abnormal cervical cytology. Dursun et al. ${ }^{21}$ reported $8 \%$ multiple HPV infection and 5\% double infection with HPV 16+18 among patients with abnormal cytology. The lower ratio of infection with multiple HPV types in our study is probably due to the population characteristics. Although both of the aforementioned studies are also from Ankara, our hospital serves in a more conservative part of the city. Additionally, the aforementioned studies reported results from two reference hospitals.

Although the relationship between age and HPV status is well known, the mean ages of HPV $(+)$ and (-) patients were similar in the present study. Dursun et al. ${ }^{25}$ reported statistically significant negative relationship between age and HPV positivity. The younger the age, the higher was the chance of HPV positivity. The possible reason for the inconsistent result of our study was the low number of subjects and the study design that only investigated HPV status in patients with abnormal cytology.

The small sample size was the major limitation of the present study. However, considering the difficulty of recruiting more patients with abnormal cervical cytology results to a single center trial, we had to perform the statistical analyses with this low number. Despite the small sample size and retrospective nature of analyses that are recognized as significant limitations of our work, the systematic exploration of individual parameters, the consistency in observed associations between HPV genotyping and abnormal cytological results add credence to our observations.

In conclusion, it's epidemiologically important to determine HPV genotype distribution in Turkey which is a developing country with more than 75 million people living and has different sociocultural perspectives in different regions as it may affect screening and vaccination strategies. Similar to differences between different countries all over the world, cervical cytological abnormality and HPV prevalence may differ between different regions of Turkey. Further population based studies with larger cohorts are needed to determine the real HPV prevalence and genotype distribution in different regions of Turkey. By this way, effective national and regional screening and vaccination strategies can be developed.

\section{Acknowledgements}

None.

\section{Conflicts of interest}

None.

\section{References}

1. Ferlay J, Soerjomataram I, Ervik M, et al. GLOBOCAN 2012 v1.0, Cancer Incidence and Mortality Worldwide: IARC Cancer Base International Agency for Research on Cancer, Lyon, France. 2013.

2. Jemal A, Bray F, Center MM, et al. Global cancer statistics. CA Cancer J Clin. 2005;61(2):69-90.

3. Baseman J, Koutsky L. The epidomiology of human papillomavirus infections. J Clin Virol. 2005;32:S16-S24.

4. Bosch XF, Burchell A, Schiffman M, et al. Epidemiology and natural history of human papillomavirus infections and type-specific implications in cervical neoplasia. Vaccine. 2008;26(Suppl 10):K1-K16.

5. Kjaer SK, Van Den Brule AJ, Paull G, et al. Type specifi c persistence of high-risk human papillomavirus (HPV) as indicator of high-grade cervical squamous intraepithelial lesions in young women: population based prospective follow-up study. BMJ. 2002;325(7364):572-578

6. Solomon D, Davey D, Kurman R, et al. The 2001 Bethesda System: terminology for reporting results of cervical cytology. JAMA. 2002;287(16):2114-2119.

7. Sigurdsson K, Sigvaldason H. Longitudinal trends in cervical cytological lesions and the effect of risk factors. A 30-year overview. Acta Obstet Gynecol Scand. 2006;85(3):350-358.

8. Karabulut A, Alan T, Ekiz MA, et al. Evaluation of cervical screening results in a population at normal risk. Int J Gynecol Obstet. 2010;110(1):40-42.

9. Celik C, Gezginç K, Toy H, et al. A comparison of liquid-based cytology with conventional cytology. Int J Gynecol Obstet. 2008;100(2):163-166.

10. Turkish Cervical Cancer and Cervical Cytology Research Group. Prevalence of cervical cytological abnormalities in Turkey. Int J Gynecol Obstet. 2009;106(3):206-209.

11. Vinodhini K, Shanmuqhapriya S, Das BC, et al. Prevalence and risk factors of HPV infection among women from various provinces of the world. Arch Gynecol Obstet. 2012;285(3):771-777.

12. Inal MM, Köse S, Yildirim Y, et al. The relationship between human papillomavirus infection and cervical intraepithelial neoplasia in Turkish women. Int J Gynecol Cancer. 200717(6):1266-1270.

13. Eren F, Erenus M, Bas E, et al. Prevalence of HPV infection by cytologic diagnosis and HPV DNA extraction and prevalence of the HPV genotypes detected in urban Turkish women. Int J Gynaecol Obstet. 2010;109(3):235-238

14. Ozcan ES, Taskın S, Ortac F. High-risk human papilloma virus prevalence and its relation with abnormal cervical cytology among Turkish women. J Obstet Gynaecol. 2011;31(7):656-658.

15. Kasap B, Yetimalar H, Keklik A, et al. Prevalence and risk factors for human papillomavirus DNA in cervical cytology. Eur J Obstet Gynecol Reprod Biol. 2011;159(1):168-171

16. Özalp SS, Us T, Arslan E, et al. HPV DNA and pap smear test results in cases with and without cervical pathology. J Turk Ger Gynecol Assoc. 201213(1):8-14.

17. Tezcan S, Ozgur D, Ulger M, et al. Human papillomavirus genotype distribution and E6/E7 oncogene expression in Turkish women with cervical cytological findings. Asian Pas J Cancer Prev. 2014;15(9):39974003 . 
18. Ergünay K, Misirlioglu M, Firat $P$, et al. Investigation of human papilloma virus DNA in cervical samples with cytological abnormalities and typing of the virus. Mikrobiyol Bul. 2007;41(2):219-226.

19. Ergünay K, Misirlioglu M, Firat P, et al. Detection and typing of human papilloma virus by polymerase chain reaction and hybridization assay in cervical samples with cytological abnormalities. Mikrobiyol Bul. 2008;42(2):273-282.

20. Yetimalar H, Koksal A, Inceoglu M, et al. HPV infection in premalign and malign cervical lesions. J Turk Soc Obstet Gynecol. 2009;6(4):273278.

21. Dursun P, Senger SS, Arslan H, et al. Human papillomavirus (HPV) prevalence and types among Turkish women at a gynecology outpatient unit. BMC Infect Dis. 2009;9:191.
22. Bayramov V, Sukur YE, Tezcan S. The value of colposcopy, high risk HPV-DNA and histopathologic examination in the management of abnormal pap smear results. J Turk Soc Obstet Gynecol. 2011;8(4):272278

23. Yuce K, Pinar A, Salman MC, et al. Detection and genotyping of cervical HPV with simultaneous cervical cytology in Turkish women: a hospitalbased study. Arch Gynecol Obstet. 2012;286(1):203-208.

24. Cilingir IU, Bengisu E, Ağaçfidan A, et al. Microarray detection of human papilloma virus genotypes among Turkish women with abnormal cytology at a colposcopy unit. J Turk Ger Gynecol Assoc. 2013;14(1):23-27.

25. Dursun P, Ayhan A, Mutlu L, et al. HPV types in Turkey: Multicenter hospital based evaluation of 6388 patients in Turkish Gynecologic Oncology Group centers. Turk Pat Derg. 2013;29(3):210-216. 